\title{
Effect of homologous synovial membrane on adult human articular cartilage in organ culture, and failure to influence it with D-penicillamine
}

\author{
R. K. JACOBY
}

From the Department of Medicine, University of Bristol

SUMMARY Adult human articular cartilage has been maintained in organ culture for 8 days, and the culture medium, which was changed on alternate days, was pooled. Normal and rheumatoid cartilage was obtained from patients and 4 types of culture were prepared: (1) cartilage alone; (2) cartilage + D-penicillamine; (3) cartilage + homologous synovium; (4) cartilage, synovium, and D-penicillamine. The hexosamines and hexuronic acid were measured in the cartilage explants and in the medium. The quantity released was divided by the amount measured in the original cartilage explant and the different culture variables were compared. D-penicillamine did not alter the release of cartilage proteoglycan, but the addition of synovium did. The rheumatoid cartilage released significantly more proteoglycan than normal cartilage whether or not homologous synovium was present.

It has been shown that D-penicillamine is an effective drug in the treatment of patients with rheumatoid arthritis (Multicentre Trial, 1973) and that joint erosions are less likely to increase in patients on this drug than in control patients. The experiments described in this paper were designed to show, on cartilage explants with adjacent synovial membrane, whether human cartilage proteoglycan catabolism could be modified by the addition of $D$ penicillamine. Experiments performed on cartilage explants from pigs have shown that adjacent synovial tissue depletes the metachromatic proteoglycan from the cartilage matrix in organ culture (Fell and Barratt, 1973).

\section{Material and methods}

Adult human cartilage was removed from the nonweight-bearing surfaces of the femoral condyles of 5 patients undergoing menisectomy, and from the unaffected areas of patellar cartilage of 6 patients with chondromalacia patellae. Diseased rheumatoid cartilage from 5 patients having total knee replacement operations was also obtained. Cartilage

Accepted for publication 8 February 1979.

Correspondence to Dr R. K. Jacoby, Department of Rheumatology, Torbay Hospital, Torquay TQ2 7AA. explants were prepared and cultured after the method of Dingle et al. (1966), and synovial membrane from the same joints was also maintained in 2 of the 4 cultures prepared from each patient. Dish $\mathbf{A}=$ cartilage alone, dish $\mathbf{B}=$ cartilage $+\mathrm{D}$ penicillamine, dish $\mathrm{C}=$ cartilage + synovium, dish $\mathrm{D}=$ cartilage + synovium $+\mathrm{D}$-penicillamine. The tissue culture medium BGJ5 (Reynolds, 1972) was used in these experiments with $5 \%$ fetal calf serum. D-penicillamine was added to the medium in dishes B and D at a concentration of $0.08 \mathrm{mg} / \mathrm{ml}$, which is the peak plasma concentration that could be expected in a patient after taking a $250 \mathrm{mg}$ capsule. The explanted tissues were maintained in culture for a period of 8 days, the medium being changed every 48 hours and the gas mixture $(20 \%$ oxygen, $5 \%$ carbon dioxide, $75 \%$ nitrogen at atmospheric pressure) renewed at the same time.

The culture medium from each dish was stored at $-20^{\circ} \mathrm{C}$, and at the end of the culture period the medium from each explant was pooled. The subsequent analyses refer to the cartilage explants alone and do not include the synovial membrane, which was discarded at the end of the culture period. The cartilage explants were dried to a constant weight over silica gel and digested in $2 \mathrm{ml}$ of buffered papain (Jacoby and Jayson, 1975).

The uronic acid content of the cartilage digest and 
the medium was estimated on $0.2 \mathrm{ml}$ of liquid by acid carbazole method (Bitter and Muir, 1962) after precipitation with cetyl pyridinimium chloride (Jacoby, 1976). The cartilage digest and the medium were prepared for hexosamine analysis by a gasliquid chromatography method which has been described in a previous paper (Jacoby, 1976).

\section{Results}

Uronic acid and hexosamine analysis of the blank medium (unexposed to cartilage and synovium) failed to reveal significant quantities of these materials. An aliquot of uncultured medium from each experiment was used as a blank.

Histological sections of 2 explants were prepared after $\mathbf{8}$ days in culture. These specimens showed loss of metachromasia of the cartilage matrix when maintained in culture with synovium. The control cultures showed no loss of metachromasia if cultured without synovium.

The hexosamine and hexuronic acid shed by the explanted tissues have been expressed as a fraction of the quantity present in the cartilage explants at the end of the culture period (Tables 1-3).

\section{EFFECT OF SYNOVIUM ON THE}

\section{CARTILAGE PROTEOGLYCANS}

The addition of synovium to the cartilage explants caused a significant increase in the galactosamine and uronic acid (from chondroitin sulphate) shed into the medium (Table 4). The quantity of glucosamine (from keratan sulphate) shed into the medium was not influenced by additional synovium.

Table 1 Uronic acid content of medium $\div$ cartilage digest, $\mu \mathrm{g} / \mathrm{mg}$ dry weight of cartilage digest

\begin{tabular}{|c|c|c|c|c|}
\hline Source of cartilage & Cartilage control culture & Cartilage $+D-p$ & Cartilage + synovium & $\begin{array}{l}\text { Cartilage }+D-p+ \\
\text { synovium }\end{array}$ \\
\hline $\mathrm{F} \mathrm{N}$ & $\frac{0.4}{5.4}=0.0727$ & $\frac{1 \cdot 4}{2 \cdot 0}=0.700$ & $\frac{2 \cdot 7}{2 \cdot 3}=1 \cdot 1739$ & $\frac{1 \cdot 8}{1 \cdot 3}=1 \cdot 3846$ \\
\hline F N & $\frac{0 \cdot 3}{3 \cdot 3}=0.0909$ & $\frac{0.9}{0.9}=1.000$ & $\frac{0.8}{0.9}=0.8889$ & $\frac{7 \cdot 4}{5 \cdot 9}=1 \cdot 2542$ \\
\hline F N & $\frac{9 \cdot 2}{5 \cdot 0}=0.0400$ & $\frac{0.8}{0.5}=1.6000$ & $\frac{2 \cdot 2}{1 \cdot 9}=1 \cdot 1579$ & $\frac{2 \cdot 4}{1 \cdot 3}=1 \cdot 8462$ \\
\hline F N & $\frac{1 \cdot 6}{1 \cdot 0}=1 \cdot 600$ & $\frac{0.6}{3.9}=0.1935$ & $\frac{2 \cdot 1}{1 \cdot 6}=1 \cdot 3125$ & $\frac{1.9}{1 \cdot 7}=1 \cdot 1176$ \\
\hline$\Gamma=N$ & $\frac{1 \cdot 8}{2 \cdot 3}-0.7826$ & $\frac{3 \cdot 2}{2 \cdot 0}=1 \cdot 6000$ & $\frac{2 \cdot 8}{1 \cdot 5}=1 \cdot 8667$ & $\frac{3 \cdot 6}{1 \cdot 5}=2 \cdot 4000$ \\
\hline$P N$ & $\frac{0.7}{1.4}=0.500$ & $\frac{0.8}{2.9}=0.2759$ & $\frac{1 \cdot 9}{1 \cdot 2}=1 \cdot 5833$ & $\frac{2 \cdot 5}{3 \cdot 6}=0.6944$ \\
\hline$P \mathrm{~N}$ & $\frac{1 \cdot 2}{1 \cdot 0}-1 \cdot 200$ & $\frac{0.9}{5 \cdot 0}=1 \cdot 8000$ & $\frac{2 \cdot 1}{1 \cdot 3}=1 \cdot 6156$ & $\frac{2 \cdot 6}{1 \cdot 9}=1 \cdot 3684$ \\
\hline$P N$ & $\frac{0 \cdot 6}{4 \cdot 0}-1 \cdot 500$ & $\frac{0.8}{3 \cdot 6}=0.2222$ & $\frac{3 \cdot 5}{3 \cdot 1}=1 \cdot 1290$ & $\frac{2.9}{3 \cdot 0}=0.9667$ \\
\hline$P \mathbf{N}$ & $\frac{0.7}{5 \cdot 2} 0 \cdot 1346$ & $\frac{1 \cdot 1}{2 \cdot 8}=0.3929$ & $\frac{3 \cdot 6}{3 \cdot 1}=1 \cdot 1613$ & $\frac{3 \cdot 3}{2 \cdot 1}=1 \cdot 5714$ \\
\hline$P \mathbf{N}$ & $\begin{array}{ll}\frac{0.6}{0.9} & 0.6667\end{array}$ & $\frac{1 \cdot 8}{3 \cdot 1}=0.5806$ & $\frac{2 \cdot 2}{1 \cdot 5}=1 \cdot 4667$ & $\frac{2 \cdot 4}{2 \cdot 0}=1 \cdot 2000$ \\
\hline$P N$ & $\frac{1 \cdot 5}{2 \cdot 8} \quad 0 \cdot 5357$ & $\frac{1 \cdot 5}{2 \cdot 3}=0.6522$ & $\frac{2.9}{1 \cdot 8}=1.6111$ & $\frac{2 \cdot 1}{2 \cdot 0}=1 \cdot 0500$ \\
\hline Mean and standard deviation & $\begin{array}{l}0.6476 \\
0.6757\end{array}$ & $\begin{array}{l}0 \cdot 8198 \\
0 \cdot 7034\end{array}$ & $\begin{array}{l}1 \cdot 3606 \\
0.4936\end{array}$ & $\begin{array}{l}1.3503 \\
0.5751 \\
\end{array}$ \\
\hline F RA & $\frac{6 \cdot 4}{1 \cdot 4} 4.5714$ & $\frac{3 \cdot 5}{0 \cdot 4}=8 \cdot 7500$ & $\frac{2 \cdot 9}{0 \cdot 9}=3 \cdot 2222$ & $\frac{3 \cdot 2}{0 \cdot 9}=3 \cdot 5556$ \\
\hline F RA & $\frac{8 \cdot 0}{2 \cdot 1}-3 \cdot 8095$ & $\frac{9 \cdot 2}{2 \cdot 0}=4 \cdot 6000$ & $\frac{10 \cdot 3}{1 \cdot 5}=6 \cdot 8667$ & $\frac{9 \cdot 0}{0 \cdot 9}=10 \cdot 000$ \\
\hline F RA & $\frac{4 \cdot 0}{1 \cdot 2} \cdot 3 \cdot 3333$ & $\frac{5 \cdot 5}{1 \cdot 7}=3 \cdot 2353$ & $\frac{3 \cdot 6}{1 \cdot 5}=2 \cdot 4000$ & $\frac{5 \cdot 0}{1 \cdot 8}=2 \cdot 7778$ \\
\hline F RA & $\frac{4 \cdot 1}{1 \cdot 1} \quad 3 \cdot 7273$ & $\frac{6 \cdot 1}{1 \cdot 2}=5 \cdot 0833$ & $\frac{12 \cdot 1}{1 \cdot 9}=6 \cdot 3684$ & $\frac{9 \cdot 3}{2 \cdot 1}=4 \cdot 4286$ \\
\hline F RA & $\frac{29 \cdot 1}{6 \cdot 0}=4 \cdot 8500$ & $\frac{2 \cdot 7}{0 \cdot 6}=4 \cdot 5000$ & $\frac{8 \cdot 1}{2 \cdot 3}=3 \cdot 5000$ & $\frac{1 \cdot 9}{0 \cdot 9}=2 \cdot 1111$ \\
\hline Mean and standard deviation & $\begin{array}{l}4.0583 \\
0.7224\end{array}$ & $\begin{array}{l}5 \cdot 2337 \\
1 \cdot 1860\end{array}$ & $\begin{array}{l}4.4715 \\
1.3103\end{array}$ & $\begin{array}{l}4 \cdot 5746 \\
1.4731\end{array}$ \\
\hline
\end{tabular}

F-Femoral crndyle. P Patella. N Normal. RA - Rheumatoid arthritis. D-p D-penicillamine. 
Table 2 Glucosamine content of medium : cartilage digest, $\mu \mathrm{g} / \mathrm{mg} \mathrm{dry}$ weight of cartilage

\begin{tabular}{|c|c|c|c|c|}
\hline Source of cartilage & Cartilage control culture & Cartilage $-D-p$ & Cartilage + synorium & $\begin{array}{l}\text { Cartilage }+D \cdot p \\
\text { synovium }\end{array}$ \\
\hline $\mathrm{F} \mathrm{N}$ & $\frac{0}{2 \cdot 1}=0.000$ & $\frac{0.2}{0.4} 0.500$ & $\frac{0.7}{0.6}=1 \cdot 1667$ & $\frac{0.8}{0.3}-2 \cdot 6667$ \\
\hline F N & $\frac{0}{1.2}=0.000$ & $\frac{0.2}{0.5}=0.400$ & $\frac{0.4}{0.4}-1.000$ & $\frac{0.4}{1 \cdot 3} \quad 0.3097$ \\
\hline F N & $\frac{0.1}{10.8}=0.0093$ & $\frac{0}{0 \cdot 3} 0 \cdot 000$ & $\frac{0.3}{3 \cdot 1}=0.0968$ & $\frac{0.5}{1.0}-0.500$ \\
\hline $\mathrm{F} \mathrm{N}$ & $\frac{0.1}{0.6}-0.1667$ & $\frac{0.9}{1 \cdot 0} \quad 0.900$ & $\frac{1 \cdot 8}{0 \cdot 8}-2 \cdot 250$ & $\frac{1 \cdot 7}{0 \cdot 7}=2 \cdot 4286$ \\
\hline F N & $\frac{0.3}{0.4} \quad 0.7500$ & $\frac{1.0}{0.7} \quad 1.4286$ & $\frac{1.1}{0.7}=1.5714$ & $\frac{1 \cdot 3}{0 \cdot 2}=6 \cdot 500$ \\
\hline $\mathbf{P} \mathbf{N}$ & $\frac{0.8}{1 \cdot 0} \quad 0.800$ & $\frac{0.7}{2 \cdot 0} \cdot 0 \cdot 3500$ & $\frac{0.8}{0.7} \quad 1.1429$ & $\frac{2 \cdot 8}{2 \cdot 1}=1 \cdot 333$ \\
\hline$P \mathbf{N}$ & $\begin{array}{l}\frac{0.9}{0.9}-1.000 \\
0.9\end{array}$ & $\begin{array}{l}\frac{0 \cdot 7}{3 \cdot 3}-0.2121 \\
0.5\end{array}$ & $\begin{array}{ll}\frac{0.6}{0.9} & 0.6667\end{array}$ & $\frac{0.8}{1 \cdot 1}=0.7273$ \\
\hline$P N$ & $\frac{0.9}{2 \cdot 1}-0.4286$ & $\frac{0.5}{2 \cdot 7} \cdot 0 \cdot 1852$ & $\frac{0.6}{2 \cdot 7}=0 \cdot 2222$ & $\frac{0.8}{1.8} 0.444$ \\
\hline$P N$ & $\frac{0 \cdot 6}{0 \cdot 5}=1 \cdot 200$ & $\frac{1 \cdot 7}{2 \cdot 4} \cdot 0 \cdot 7083$ & $\frac{1 \cdot 0}{1 \cdot 3} \quad 0.7692$ & $\frac{0.8}{0.8}=1 \cdot 000$ \\
\hline$P \mathbf{N}$ & $\frac{0 \cdot 8}{1 \cdot 1}-0.7273$ & $\frac{0.9}{1 \cdot 5}-0.600$ & $\frac{0.9}{1.6} \cdot 0.5625$ & $\frac{0 \cdot 8}{1 \cdot 0} \quad 0 \cdot 8000$ \\
\hline Mean and standard deviation & $0.5082: 0.4473$ & $0.5284 \div 0.4126$ & $0.8401: 0.6756$ & $1 \cdot 6710 \pm 1 \cdot 8805$ \\
\hline F RA & $\frac{2 \cdot 51}{1 \cdot 3} \quad 1 \cdot 9231$ & $\frac{1 \cdot 6}{0.8} \cdot 2 \cdot 000$ & $\frac{1 \cdot 0}{0 \cdot 2}=5 \cdot 000$ & $\frac{1 \cdot 6}{0 \cdot 2}=8 \cdot 000$ \\
\hline F RA & $\frac{2 \cdot 9}{1 \cdot 9} \cdot 1 \cdot 5263$ & $\frac{2.7}{1 \cdot 1} \quad 2.4545$ & $\frac{4 \cdot 3}{1 \cdot 3} \quad 3 \cdot 3077$ & $\frac{1 \cdot 5}{0.9} \quad 1.6667$ \\
\hline F RA & $\frac{2 \cdot 5}{0 \cdot 6}-4 \cdot 1667$ & $\frac{4 \cdot 5}{1 \cdot 0}=4 \cdot 500$ & $\frac{1 \cdot 6}{0 \cdot 7} 2 \cdot 285$ & $\frac{3 \cdot 6}{0 \cdot 6} 6 \cdot 000$ \\
\hline F RA & $\frac{3 \cdot 4}{0 \cdot 8} \cdot 4 \cdot 2500$ & $\frac{2 \cdot 5}{1 \cdot 5} \quad 1 \cdot 6667$ & $\frac{4 \cdot 1}{1 \cdot 1}=3 \cdot 7273$ & $\frac{2 \cdot 1}{0.9} \cdot 2 \cdot 333$ \\
\hline F RA & $\frac{20 \cdot 1}{4 \cdot 2}=4 \cdot 7857$ & $\frac{2 \cdot 7}{0 \cdot 9} \cdot 3 \cdot 000$ & $\frac{3 \cdot 4}{0 \cdot 4}=8 \cdot 500$ & $\frac{1 \cdot 3}{0 \cdot 2} 6 \cdot 500$ \\
\hline Mean and standard deviation & $3 \cdot 3304: 1 \cdot 4915$ & $2 \cdot 7242 \leq 1 \cdot 1119$ & $2 \cdot 6847: 2 \cdot 9674$ & $4.8999 \div 2.7579$ \\
\hline
\end{tabular}

F. Femoral condyle. $\mathbf{P}-$ Patella. $\mathbf{N}=$ Normal. RA Rheumatoid arthritis. $\mathbf{D}$-p $=$ D-penicillamine.

PROTEOGLYCANS SHED FROM NORMAL

\section{AND RHEUMATOID CARTILAGE}

There was a highly significant increase in the hexosamine and uronic acid loss from the rheumatoid cartilage compared with normal cartilage (Table 5).

\section{EFFECT OF D-PENICILLAMINE ON THE}

\section{CARTILAGE PROTEOGLYCANS}

There was no difference between the explants maintained with D-penicillamine and those explants cultured without this drug (Table 6).

\section{Discussion}

In the living joint the protein polysaccharide chains are secreted by chondrocytes into the cartilage matrix and by synovial cells into the synovial fluid. The major protein polysaccharides found in cartilage are chondroitin sulphate and keratan sulphate, whereas the synovial fluid contains hyaluronic acid, which is also present in much smaller amounts in the articular cartilage. In tissue culture, as in vivo, these glycosaminoglycans are being synthesised and degraded throughout the culture period and shed into the medium. After papain digestion of the medium the chains are split into their hexose components, however, and it is impossible to distinguish from which tissue-that is, synovium or cartilage - the individual molecules were derived. The problem is largely overcome by measuring the hexose molecules, uronic acid, glucosamine, and galactosamine. Galactosamine is found only in chondroitin sulphate and thus cartilage tissue, whereas uronic acid is found in both cartilage chondroitin sulphate and synovial hyaluronic acid. Glucosamine on the other hand is found in both hyaluronic acid and the other cartilage glycosaminoglycan, namely, keratan sulphate. The distribution and concentration of the cartilage glycosaminoglycans are well known and have been fully reviewed elsewhere (Muir, 1973). However, suffice it to say that chondroitin sulphate is present 
Table 3 Galaciosamine content of medium $\div$ cartilage digest, $\mu \mathrm{g} / \mathrm{mg}$ dry weight of cartilage

\begin{tabular}{|c|c|c|c|c|}
\hline Source of cartilage & Cartilage control culture & Cartilage $+D-p$ & Cartilage + synovium & $\underset{\text { synovium }}{\text { Cartilage }}+D-p+$ \\
\hline $\mathrm{F} \mathrm{N}$ & $\frac{0.2}{4 \cdot 5}=0.0444$ & $\frac{1 \cdot 1}{1.4}=0.7857$ & $\frac{2 \cdot 4}{2 \cdot 2}=1.0909$ & $\frac{1 \cdot 8}{1 \cdot 5}=1 \cdot 200$ \\
\hline F N & $\frac{0.3}{3 \cdot 1}=0.0986$ & $\frac{0.7}{1.6}=0.4375$ & $\frac{0.9}{1 \cdot 1}=0.8182$ & $\frac{4 \cdot 8}{5 \cdot 1}=0.9412$ \\
\hline F N & $\frac{0.5}{13 \cdot 2} 0.0379$ & $\frac{0.5}{0.3}=1.6667$ & $\frac{2 \cdot 9}{2 \cdot 4}=1 \cdot 2083$ & $\frac{2 \cdot 8}{1 \cdot 3}=2 \cdot 1538$ \\
\hline F N & $\frac{1 \cdot 3}{1 \cdot 2}=1 \cdot 0833$ & $\frac{0.4}{2 \cdot 5}=0 \cdot 1600$ & $\frac{2 \cdot 3}{1 \cdot 9}=1 \cdot 2105$ & $\frac{1 \cdot 8}{1 \cdot 7}=1 \cdot 0588$ \\
\hline F N & $\frac{1 \cdot 1}{1 \cdot 4}-0.7857$ & $\frac{3 \cdot 0}{1 \cdot 9}=1 \cdot 5789$ & $\frac{2 \cdot 9}{1 \cdot 7}=1 \cdot 7059$ & $\frac{3 \cdot 0}{0.9}=3 \cdot 333$ \\
\hline $\mathrm{F} N$ & $\frac{0.8}{1.45} 0.5517$ & $\frac{0.8}{3.4}=0.2353$ & $\frac{1.3}{0.9}=1.444$ & $\frac{2.9}{3 \cdot 0}=0.9667$ \\
\hline F N & $\frac{1.9}{1 \cdot 3}=1.4615$ & $\frac{1 \cdot 2}{5 \cdot 7}=0 \cdot 2105$ & $\frac{2 \cdot 8}{1 \cdot 5}=1 \cdot 8667$ & $\frac{2 \cdot 0}{1 \cdot 8}=1 \cdot 111$ \\
\hline F N & $\frac{0.4}{3 \cdot 6}-0.1111$ & $\frac{0.6}{3 \cdot 8}=0.1579$ & $\frac{3 \cdot 9}{3 \cdot 3}=1 \cdot 1818$ & $\frac{2 \cdot 9}{2 \cdot 9}=1 \cdot 000$ \\
\hline $\mathrm{P} \mathrm{N}$ & $\frac{0 \cdot 7}{5 \cdot 7}-1 \cdot 228$ & $\frac{1 \cdot 4}{3 \cdot 5}=0.4$ & $\frac{3 \cdot 9}{3 \cdot 0}=1 \cdot 300$ & $\frac{3 \cdot 9}{2 \cdot 1}=1 \cdot 8571$ \\
\hline$P N$ & $\frac{0.9}{1.4}=0.6429$ & $\frac{1 \cdot 7}{3 \cdot 1}=0 \cdot 5484$ & $\frac{2 \cdot 8}{1 \cdot 8}=1 \cdot 5556$ & $\frac{2 \cdot 8}{2 \cdot 1}=1 \cdot 333$ \\
\hline$P \mathrm{~N}$ & $\frac{1 \cdot 5}{2 \cdot 3}=0.6522$ & $\frac{1 \cdot 0}{2 \cdot 0}=0 \cdot 500$ & $\frac{2 \cdot 6}{1 \cdot 7}=1 \cdot 5294$ & $\frac{1 \cdot 9}{0 \cdot 9}=2 \cdot 111$ \\
\hline Mean and standard deviation & $\begin{array}{l}0.6087 \\
0.5028\end{array}$ & $\begin{array}{l}0.6074 \\
0.5369\end{array}$ & $\begin{array}{l}1 \cdot 3556 \\
0.2995\end{array}$ & $\begin{array}{l}1.5515 \\
0.7464\end{array}$ \\
\hline F RA & $\frac{6 \cdot 7}{1 \cdot 9}=3 \cdot 5263$ & $\frac{3 \cdot 8}{0.6}=6.333$ & $\frac{2 \cdot 8}{0 \cdot 4}=7 \cdot 000$ & $\frac{3 \cdot 3}{0 \cdot 5}=6 \cdot 600$ \\
\hline F RA & $\frac{7 \cdot 1}{1 \cdot 9}=3.7368$ & $\frac{9 \cdot 5}{2 \cdot 5}=4 \cdot 5238$ & $\frac{10 \cdot 4}{1.4}=7.4286$ & $\frac{8 \cdot 0}{1 \cdot 1}=7 \cdot 2726$ \\
\hline F RA & $\frac{4 \cdot 4}{1 \cdot 2}-3 \cdot 6667$ & $\frac{5 \cdot 9}{1 \cdot 7}=3 \cdot 4706$ & $\frac{3 \cdot 2}{1 \cdot 1}=2 \cdot 9091$ & $\frac{4 \cdot 7}{0 \cdot 8}=5 \cdot 875$ \\
\hline F RA & $\frac{4 \cdot 8}{1 \cdot 4} \quad 3 \cdot 4286$ & $\frac{6 \cdot 1}{1 \cdot 7}=3 \cdot 5882$ & $\frac{12 \cdot 2}{1 \cdot 5}=8 \cdot 1333$ & $\frac{9 \cdot 1}{1 \cdot 4}=6 \cdot 500$ \\
\hline F RA & $\frac{29 \cdot 8}{6 \cdot 7} \quad 4 \cdot 4478$ & $\frac{2 \cdot 2}{0.9}=3 \cdot 000$ & $\frac{8 \cdot 8}{4 \cdot 1}=2 \cdot 100$ & $\frac{1.5}{0.5}=3.000$ \\
\hline Mean and standard deviation & $\begin{array}{l}3 \cdot 762 \\
0.4\end{array}$ & $\begin{array}{l}4 \cdot 1832 \\
1 \cdot 3229\end{array}$ & $\begin{array}{l}9 \cdot 2942 \\
6 \cdot 8536\end{array}$ & $\begin{array}{l}5 \cdot 8495 \\
1.6682\end{array}$ \\
\hline
\end{tabular}

$\mathrm{F} \therefore$ Femoral condyle. $\mathrm{P}$. Patella. $\mathrm{N}=$ Normal. $\mathrm{RA}=$ Rheumatoid arthritis. $\mathrm{D}-\mathrm{p}=\mathrm{D}$-penicillamine.

in greater amounts than keratan sulphate, more so in young cartilage and osteoarthrotic cartilage.

The pattern of secretion into the medium certainly differs between the hexose molecules and must reflect the different protein polysaccharide chains from which they were degraded.

The results uniformly suggest that $\mathrm{D}$-penicillamine does not alter the release of any of the hexose molecules from normal or rheumatoid cartilage, which implies that any beneficial effect of this drug noted in rheumatoid arthritis (Multicentre Trial Group, 1973) is not due to a cartilage sparing effect as such.

The influence of synovial tissue on articular cartilage in tissue culture would appear to be deleterious, which raises questions as to the validity of this model. Fell and Barratt (1973) have shown a similar reversible deleterious effect of synovium and subchondral bone marrow on the explanted cartilage of pigs, and more recently Fell and Jubb (1977) have shown that minced synovial tissue alone with cartilage will disturb the matrix proteoglycans. In the undamaged joint synovium and cartilage are found together, and even in traumatised cartilage the synovium does not digest the exposed deeper layers, so why does the tissue culture model behave differently? The answer is not yet known. However, it is well known that in rheumatoid arthritis synovium can digest the cartilage matrix, and so rheumatoid arthritis may have something in common with the in-vitro model using cartilage synovium.

The chemical changes observed in the medium of explants exposed to synovium showed that galactosamine and uronic acid were substantially increased as a result. This may suggest that chondroitin sulphate degradation had occurred. The quantity of glucosamine released into the medium was not 
Table 4 The effect of synovium on the cartilage. The galactosamine, uronic acid, and glucosamine shed from the cartilage exposed to synovium has been tested against the cultures maintained without synovium. The upper figure in each box is the value of Student's $t$ and the lower figure indicates the significance $(N S=$ not significant)

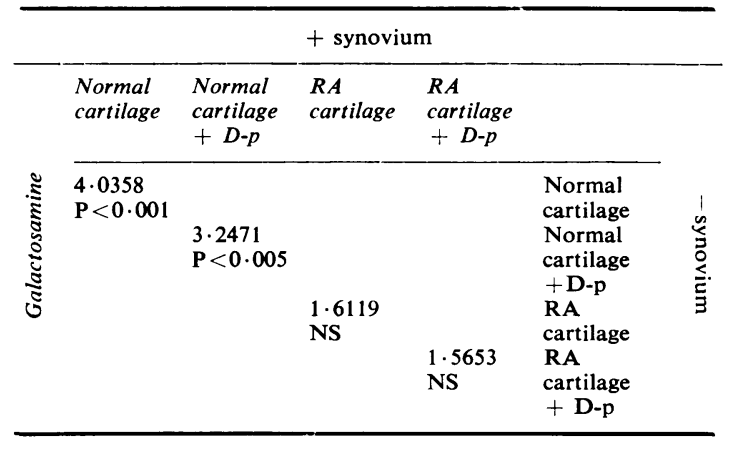

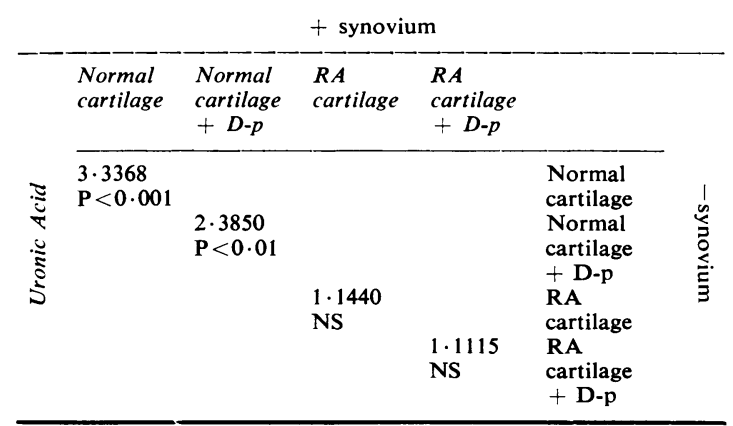

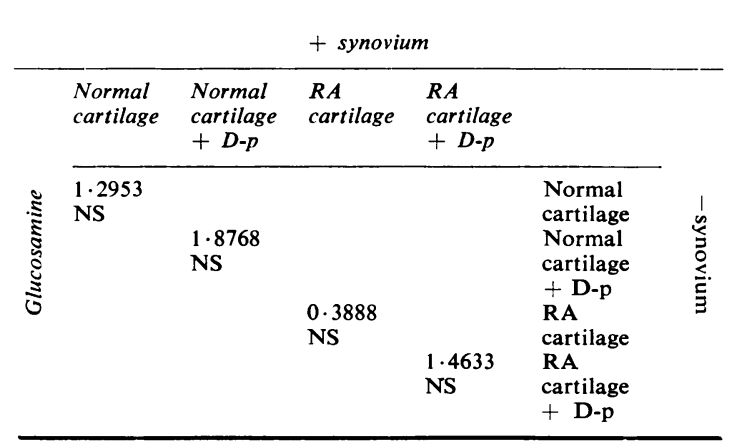

significantly different in the synovial versus nonsynovial treated explants. This evidence suggests that neither synovial hyaluronic acid nor cartilage keratan sulphate were being shed in sufficient quantities to make any difference. There is no reason to indicate that chondroitin sulphate was selectively broken down rather than keratan sulphate, so one must conclude that keratan sulphate was shed whether thesynovium was present or not. It is unlikely that keratan sulphate was completely absent from
Table 5 The difference between normal cartilage and rheumatoid cartilage. The value for Student's $\mathrm{t}$ and the significance is given as in Table 4

\begin{tabular}{|c|c|c|c|c|c|c|}
\hline \multicolumn{7}{|c|}{ Normal Cartilage } \\
\hline \multirow[b]{2}{*}{ 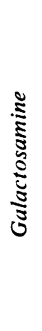 } & Control & $+D-p$ & $\stackrel{+}{\text { synovium }}$ & $\begin{array}{l}+ \\
\text { synovium } \\
+D-p\end{array}$ & & \\
\hline & $\begin{array}{l}11 \cdot 5434 \\
P<0.001\end{array}$ & $\begin{array}{l}7 \cdot 1845 \\
P<0.001\end{array}$ & $\begin{array}{l}3 \cdot 5860 \\
P<0.005\end{array}$ & $\begin{array}{l}6 \cdot 6600 \\
P<0 \cdot 001\end{array}$ & $\begin{array}{l}\text { Control } \\
+ \text { D-p } \\
+ \\
\text { synovium } \\
+ \\
\text { synovium } \\
+ \text { D-p }\end{array}$ & 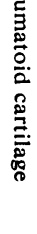 \\
\hline \multicolumn{7}{|c|}{ Normal Cartilage } \\
\hline \multirow{3}{*}{ 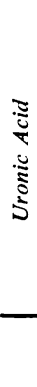 } & Control & $+D-p$ & $\stackrel{+}{\text { synovium }}$ & $\begin{array}{l}+ \\
\text { synovium } \\
+D-p\end{array}$ & & 중 \\
\hline & $\begin{array}{l}9.4427 \\
P<0.001\end{array}$ & $\begin{array}{l}7.4433 \\
P<0.001\end{array}$ & $\begin{array}{l}3 \cdot 5008 \\
\mathrm{P}<0 \cdot 005\end{array}$ & $\begin{array}{l}4 \cdot 3776 \\
P<0 \cdot 001\end{array}$ & $\begin{array}{l}\text { Control } \\
+ \text { D-p } \\
+ \\
\text { synovium } \\
+ \\
+ \text { D-p }\end{array}$ & 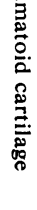 \\
\hline & \multicolumn{6}{|c|}{ Normal Cartilage } \\
\hline \multirow[b]{2}{*}{ 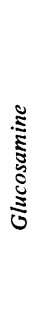 } & Control & $+D-p$ & + synoviu & $\begin{array}{l}m+ \\
\text { synovium } \\
+D-p\end{array}$ & & \\
\hline & $\begin{array}{l}5 \cdot 3657 \\
P<0.001\end{array}$ & $\begin{array}{l}5.3674 \\
P<0.001\end{array}$ & $\begin{array}{l}3 \cdot 5760 \\
P<0.005\end{array}$ & $\begin{array}{l}2.5538 \\
\mathbf{P}<0.025\end{array}$ & $\begin{array}{l}\text { Control } \\
+ \text { D-p } \\
+ \\
\text { synovium } \\
+ \\
\text { synovium } \\
+ \text { D-p }\end{array}$ & 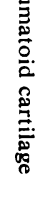 \\
\hline
\end{tabular}

the explants, since the glucosamine that was measured in the medium can hardly have come entirely from synovial hyaluronic acid.

The number of experiments using rheumatoid cartilage is very small, and the value for Student's $t$ must be interpreted with some caution. However, the differences between the diseased and normal explants were substantial in the absence of synovium suggesting a real difference. In those cultures comparing the 2 different types of cartilage all 3 hexose molecules were secreted in excess from the diseased cartilage. This evidence supports the contention that, as in osteoarthrotic cartilage, rheumatoid cartilage is also metabolically more active than normal cartilage (Jacoby and Jayson, 1976). The picture is less clear in the explants maintained with 
Table 6 The difference between cartilage cultured with and without D-penicillamine. The value for Student's $\mathrm{t}$ and the significance are given as in Table 4.

\begin{tabular}{|c|c|c|c|c|c|c|}
\hline & $\begin{array}{l}\text { Normal } \\
\text { cartilage }\end{array}$ & $\begin{array}{l}\text { Normal } \\
\text { cartilage } \\
+ \\
\text { synovium }\end{array}$ & $\begin{array}{l}\boldsymbol{R A} \\
\text { cartilage }\end{array}$ & $\begin{array}{l}\text { RA } \\
\text { cartilage } \\
+ \\
\text { synovium }\end{array}$ & & \\
\hline 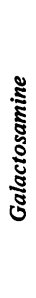 & $\begin{array}{l}0.003 \\
\text { NS }\end{array}$ & $\begin{array}{l}0.7703 \\
\text { NS }\end{array}$ & $\begin{array}{l}0.6104 \\
\text { NS }\end{array}$ & $\begin{array}{l}0.9767 \\
\text { NS }\end{array}$ & $\begin{array}{l}\text { Normal } \\
\text { cartilage } \\
\text { Normal } \\
\text { cartilage } \\
+ \\
\text { synovium } \\
\text { RA } \\
\text { cartilage } \\
\text { RA } \\
\text { cartilage } \\
+ \\
\text { synovium }\end{array}$ & 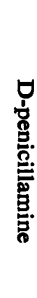 \\
\hline
\end{tabular}

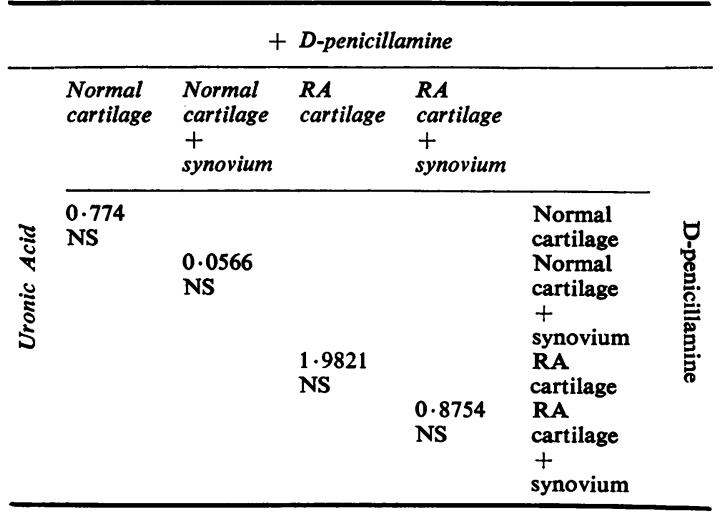

\begin{tabular}{|c|c|c|c|c|c|c|}
\hline \multicolumn{7}{|c|}{$+D$-penicillamine } \\
\hline \multirow[b]{2}{*}{ } & $\begin{array}{l}\text { Normal } \\
\text { cartilage }\end{array}$ & $\begin{array}{l}\text { Normal } \\
\text { cartilage } \\
+ \\
\text { synovium }\end{array}$ & $\begin{array}{l}\boldsymbol{R A} \\
\text { cartilage }\end{array}$ & $\begin{array}{l}\boldsymbol{R A} \\
\text { cartilage } \\
+ \\
\text { synovium }\end{array}$ & & \\
\hline & $\begin{array}{l}0 \cdot 1051 \\
\text { NS }\end{array}$ & $\begin{array}{l}1 \cdot 3150 \\
\mathrm{NS}\end{array}$ & $\begin{array}{l}0.6517 \\
\text { NS }\end{array}$ & $\begin{array}{l}1.0936 \\
\text { NS }\end{array}$ & $\begin{array}{l}\text { Normal } \\
\text { cartilage } \\
\text { Normal } \\
\text { cartilage } \\
+ \\
\text { synovium } \\
\text { RA } \\
\text { cartilage } \\
\text { RA } \\
\text { cartilage } \\
+ \\
\text { synovium }\end{array}$ & 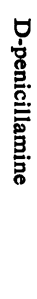 \\
\hline
\end{tabular}

synovium, since the D-penicillamine-treated cultures again showed the increased secretion of all the hexose molecules, whereas those cultures maintained with synovium alone did not. The evidence points to the fact that the synovium had little or no influence on the release of the glycosaminoglycans from the explants, and in view of the small number of experiments using rheumatoid cartilage not too much emphasis should be placed on the difference between galactosamine release and the other 2 hexose molecules. If galactosamine was truly different in the rheumatoid explants, the same should have applied to the uronic acid as the other component of chondroitin sulphate.

\section{Conclusion}

These experiments show that D-penicillamine does not appear to influence cartilage catabolism in this test system, but synovium apparently does. In rheumatoid cartilage there is a very active metabolism which does not seem to be altered by the presence or absence of homologous synovium in vitro.

The author thanks the Arthritis and Rheumatism Council for its support.

\section{References}

Bitter, T., and Muir, H. M. (1962). A modified uronic acif carbazole reaction. Analytical Biochemistry, 4, 330-334.

Dingle, J. T., Fell, H. B., and Lucy, T. A. (1966). Synthesis of connective tissue components. Biochemical Journal, 98 173-181.

Fell, H. B., and Barratt, M. E. J. (1973). The role of soft connective tissue in the breakdown of pig articular cartilage cultivated in the presence of complement sufficient antiserum to pig erythrocytes. I. Histological changes. International Archives of Allergy, 44, 441-454.

Fell, H. B., and Jubb, R. W. (1977). The effect of synovial tissue on the breakdown of articular cartilage in organ culture. Arthritis and Rheumatism, 20, 1359-1371.

Jacoby, R. K. (1976). The effect of hydrocortisone acetate on adult human articular cartilage. Journal of Rheumatology, 3, 384-389.

Jacoby, R. K., and Jayson, M. I. V. (1975). Organ culture of adult human articular cartilage. I. The effect of hyperoxia on synthesis of glycosaminoglycan. Journal of Rheumatology, 2, 270-279.

Jacoby, R. K., and Jayson, M. I. V. (1976). The synthesis of glucosaminoglycan in adult human articular cartilage in organ culture. A study of cartilage from patients with rheumatoid arthritis. Annals of the Rheumatic Diseases, 35, 32-36.

Muir, I. H. M. (1973). Biochemistry-composition of cartilage matrix. In Adult Articular Cartilage, Edited by M.A.R. Freeman. p. 100. Pitman Medical: London.

Multicentre Trial Group (1973). Controlled trial of Dpenicillamine in severe rheumatoid arthritis. Lancet, 1, 275-278.

Reynolds, J. (1972). Skeletal tissues in culture. In Biochemistry and Physiology of Bone, vol. 1, pp. 69-126. Edited by G. Bourne, Academic Press: London. 